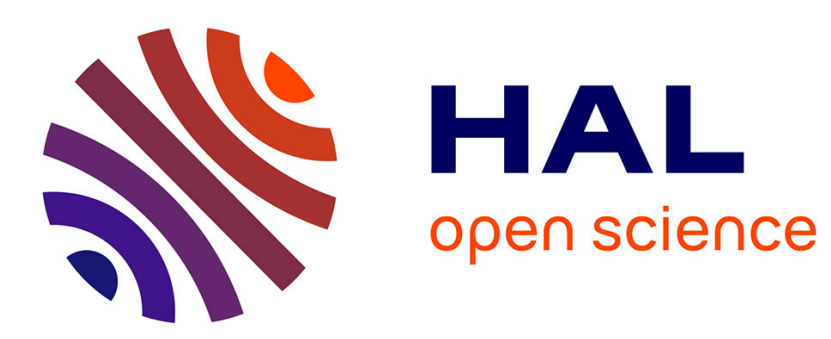

\title{
Bearing capacity of a foundation resting on a soil improved by a group of columns
}

\author{
M. Bouassida, P. de Buhan, L. Dormieux
}

\section{To cite this version:}

M. Bouassida, P. de Buhan, L. Dormieux. Bearing capacity of a foundation resting on a soil improved by a group of columns. Geotechnique, 1996, 46, pp.570-572. 10.1680/geot.1995.45.1.25 . hal-00111511

\section{HAL Id: hal-00111511 \\ https://hal.science/hal-00111511}

Submitted on 5 Aug 2019

HAL is a multi-disciplinary open access archive for the deposit and dissemination of scientific research documents, whether they are published or not. The documents may come from teaching and research institutions in France or abroad, or from public or private research centers.
L'archive ouverte pluridisciplinaire HAL, est destinée au dépôt et à la diffusion de documents scientifiques de niveau recherche, publiés ou non, émanant des établissements d'enseignement et de recherche français ou étrangers, des laboratoires publics ou privés. 


\title{
Bearing capacity of a foundation resting on a soil reinforced by a group of columns
}

\author{
M. BOUASSIDA*, P. DE BUHAN $\dagger$ and L. DORMIEUX $\dagger$
}

\begin{abstract}
A new design method for a foundation on a soil reinforced by columns is described. A lower bound of the bearing capacity is determined within the framework of the yield design theory. It takes into account the three-dimensional nature of the problem and is applicable to a wide range of geometries. A parametric study on the improvement of the bearing capacity as a function of the proportion of reinforcement, and on the strength characteristics, is presented. A complete analytical solution is given for the strength of a composite cell subjected to a triaxial loading, which provides an insight into the reinforcement mechanism.
\end{abstract}

KEYWORDS: bearing capacity, design, failure, footings/foundations, ground improvement, reinforced soils.
Le présent article propose une méthode de dimensionnement d'une foundation sur un sol renforcé par colonnes, basée sur la théorie du calcul à la rupture. Une borne inférieure de la capacité portante est obtenue en tenant compte de la nature tridimensionnelle de l'ouvrage. Elle est applicable pour une grande variété de géométries. On présente une étude paramétrique sur l'amélioration de la capacité portante en fonction de la proportion de renforcement et des caractéristiques du matériau renforçant et du matériau initial. On s'intéresse en outre à la résistance en compression d'une éprouvette composite soumise à un chargement triaxial classique, pour laquelle une solution complète est fournie sous forme analytique. Elle apporte un éclairage intéressant sur le mécanisme du renforcement par colonnes.

\section{INTRODUCTION}

As a soil improvement method, the columns reinforcement technique has three purposes: to reduce the settlement of highly compressible soils such as soft clays, to accelerate the stage of primary consolidation, and to enhance the bearing capacity. This Paper is concerned with the last of these.

Common materials for columns are well graded clean sands, gravels or stones, hence the term stone columns (Aboshi, Ichimoto, Enoki \& Harada, 1979; Soyez, 1985). However, the reduction of settlements rather than the bearing capacity of stone column reinforced foundations is generally the primary consideration when designing such structures (Balaam \& Booker, 1985; Schweiger \& Pande, 1986). As far as bearing capacity is concerned, a remarkable performance can be obtained by mixing the native soil with a low percentage of lime (the lime

\footnotetext{
* Formerly Laboratoire de Mécanique des Solides, Palaiseau, France, now Ecole Nationale des Ingénieurs de Tunis.

$\dagger$ Ecole Polytechnique, Palaiseau.
}

columns technique, Broms \& Boman, 1979). The strength of the column material can be described by a Mohr-Coulomb criterion (with appropriate friction angle and cohesion) while the native soil is modelled as a purely cohesive material.

Design calculations concerning the bearing capacity of such reinforced soils have mainly been presented for a trench-like reinforcement under the plane strain assumption (Madhav \& Vitkar, 1978; Pruchnicki \& Shahrour, 1991) and for an isolated column in an axisymmetric condition (Hughes \& Withers, 1974; Brauns, 1978). Few attempts have been made to deal with the case of a soil reinforced by a group of columns.

In the first part of the Paper, the strength of a composite cylindrical cell subjected to triaxial test conditions is investigated within the rigorous theoretical framework of the yield design theory (Chen, 1975; Salençon, 1983, 1990). The solution of this auxiliary problem provides an interesting insight into the way in which the native soil is actually reinforced by the introduction of columns. The second part is devoted to the case of a group of columns. A lower-bound solution for the bearing capacity of a foundation resting on reinforced soil is derived on the basis of the previously determined solution, and a quantitative analysis of the gain of strength due to the reinforcement is developed. 


\section{COMPOSITE CELL SUBJECTED TO THE TRIAXIAL TEST}

Consider a cylindrical composite cell $\mathscr{C}$ of height $h$ made up of a circular reinforcement column surrounded by the native soil. The shape of the cross-section of the cell by any plane $z=z_{0}$ is not specified. To illustrate this, a square-shaped cell is shown in Fig. 1. The reinforcement column occupies the domain $r<a$ and is composed of a frictional-cohesive material whose strength is described by a Mohr-Coulomb criterion

$$
\begin{aligned}
\mathrm{f}_{1}(\boldsymbol{\sigma})= & \sigma_{1}(1-\sin \varphi)-\sigma_{3}(1+\sin \varphi) \\
& -2 C^{\mathrm{c}} \cos \varphi \leqslant 0
\end{aligned}
$$

where $\sigma_{1}$ and $\sigma_{3}$ are the major and minor principal components respectively of the stress tensor o. Compressive stresses are taken as positive.

The domain outside the column $(r>a)$ is occupied by the native soil, which is a purely cohesive material. Its strength is described by a Tresca criterion

$$
\mathrm{f}_{2}(\boldsymbol{\sigma})=\sigma_{1}-\sigma_{3}-2 C \leqslant 0
$$

Both criteria are expressed in terms of total stresses and are therefore relevant for a shortterm analysis. The ratio of the cross-sectional area $\pi a^{2}$ of the reinforcing column to the total cross-sectional area $S$ of the cell is denoted by $\eta$, the proportion of the reinforcement.

This composite cell is subjected to classical triaxial test conditions. The cell is in contact with two smooth and rigid plates located in the planes $z=0$ and $z=h$. The lower plate is kept fixed while the upper one is given a vertical downward translation motion of velocity $V$. The force exerted by the upper plate on the cell is denoted by $Q=-Q e_{z}(Q>0$ when the vector $Q$ is oriented downwards). A uniform confining pressure $p$ is acting on the lateral surface, which is referred to as $\partial \mathscr{C}_{\mathbf{L}}$. Thus, the loading of the cell is character-

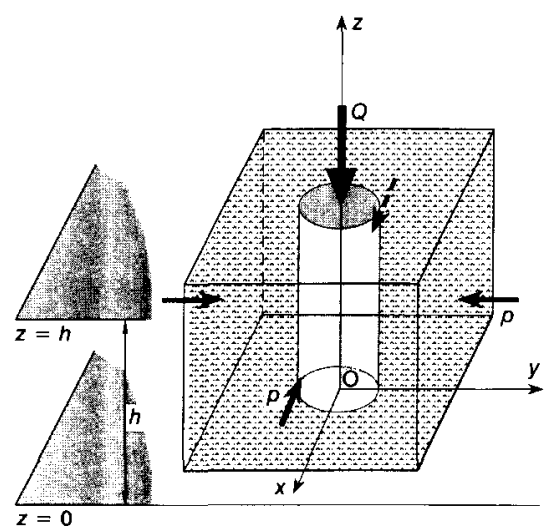

Fig. 1. Composite cell under triaxial loading ized by the two parameters $p$ and $Q$. A statically admissible (SA) stress field $\boldsymbol{\sigma}$ and a kinematically admissible (KA) velocity field $\boldsymbol{U}$ are respectively subjected to the following conditions

(a) $\sigma$ SA with $p$ and $Q$

$$
\begin{aligned}
& \partial\left(\sigma_{i, j}\right) / \partial x_{j}=0 \\
& \sigma_{i j} n_{j}=p n_{i} \text { on } \partial \mathscr{C}_{\mathrm{L}}\left(\boldsymbol{n}=n_{i} \boldsymbol{e}_{i},\right. \text { inward } \\
& \left.\quad \text { oriented unit vector normal to } \partial \mathscr{C}_{\mathrm{L}}\right) \\
& \sigma_{x z}=\sigma_{y z}=0 \text { for } z=0 \text { and } h \\
& Q=\int_{z=h} \sigma_{z z} \mathrm{~d} S
\end{aligned}
$$

The convention of summation over repeated subscripts is adopted in equations (3a) and (3b) with $i$ or $j=x, y, z$.

(b) $U$ KA with $V$

$$
U_{z}=0 \text { for } z=0 ; U_{z}=-V \text { for } z=h
$$

Generally, a given load $(Q, p)$ is said to be safe (in the sense of limit analysis or yield design) if it can be equilibrated by a stress field that complies with the strength criterion everywhere in the cell. The aim of this section is to determine the domain $K$ of safe loads $(Q, p)$ restricted to the region defined by $Q \geqslant 0$ and $p \geqslant 0$. Practically, this involves determining, for a given pressure $p$, the maximum value of $Q$ such that $(Q, p)$ is a safe load. This value is referred to as $Q^{+}(p)$

$$
Q^{+}(p)=\max [Q>0,(Q, p) \in K]
$$

The set of points $\left(Q^{+}(p), p\right)$ for $p>0$ defines the boundary of $K$ (Fig. 2). $Q^{+}(p)$ can be determined by a combination of the so-called static and kinematic approaches, which are now described.

\section{Lower-bound estimate of $K$ : static approach}

The static approach simply involves implementing this definition of $K$. Thus, in order to

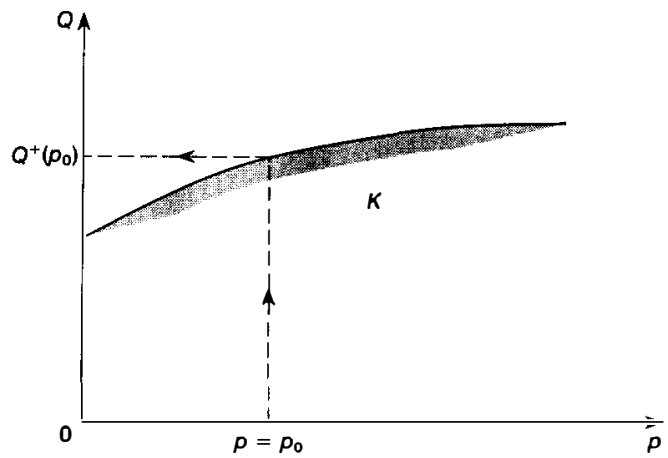

Fig. 2. Domain $K$ of safe loads $(p, Q)$ 
prove that a given load $(Q, p)$ belongs to $K$, it is necessary to exhibit a stress field $\sigma$ that is SA with $(Q, p)$ (i.e. that satisfies equation (3)) and complies with the strength criteria (equation (1) in the domain $r<a$ and equation (2) in the remaining part of the cell $(a<r)$ ).

Static approach using a piece-wise constant stress field. A first static approach to $K$ can be achieved very simply on the basis of a stress field $\sigma$ taking a constant value $\sigma^{s}$ in the native soil and another constant value $\boldsymbol{\sigma}^{\mathbf{c}}$ in the column, so that the equilibrium equation (3a) is automatically satisfied. The stress tensors $\boldsymbol{\sigma}^{\mathbf{s}}$ and $\boldsymbol{\sigma}^{\mathbf{c}}$ are chosen in order to satisfy equations (3b) and (3c), as well as

$$
\mathrm{f}_{1}\left(\boldsymbol{\sigma}^{\mathrm{c}}\right)=0 ; \quad \mathrm{f}_{2}\left(\boldsymbol{\sigma}^{\mathrm{s}}\right)=0
$$

The continuity of the stress vector acting on the interface of the native soil and the column implies the continuity of the following components (in cylindrical co-ordinates)

$$
{\sigma_{r r}}^{s}=\sigma_{r r}^{c} ; \quad \sigma_{\theta r}{ }^{s}=\sigma_{\theta r}^{c} ; \quad \sigma_{z r}^{s}=\sigma_{z r}^{c}
$$

A solution to the requirements given is

$a<r$

$$
\left.\begin{array}{l}
{\sigma_{r r}^{\mathrm{s}}}^{\mathrm{s}}=\sigma_{\theta \theta}^{\mathrm{s}}=p \\
{\sigma_{z z}^{\mathrm{s}}}^{\mathrm{s}}=p+2 C \\
\text { other } \sigma_{i j}=0
\end{array}\right\}
$$

$r<a$

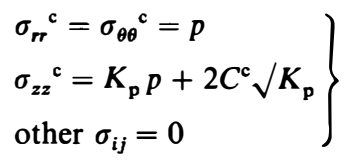

where $K_{\mathrm{p}}=(1+\sin \varphi) /(1-\sin \varphi)$ denotes the usual coefficient of passive stress.

The vertical force equilibrated by the stress field $\boldsymbol{\sigma}$ defined in equation (7) is therefore, from equation (3d)

$$
\begin{aligned}
\int_{z=h} \sigma_{z z} \mathrm{~d} S= & S\left[p\left(1-\eta+K_{\mathrm{p}} \eta\right)\right. \\
& \left.+2 C(1-\eta)+2 C^{\mathrm{c}} \eta \sqrt{ } K_{\mathrm{p}}\right]
\end{aligned}
$$

which provides a first lower-bound estimate for $Q^{+}(p)$

$$
\begin{aligned}
Q^{+}(p) / S \geqslant & {\left[p\left(1-\eta+K_{\mathrm{p}} \eta\right)\right.} \\
& \left.+2 C(1-\eta)+2 C^{\mathrm{c}} \eta \sqrt{ } K_{\mathrm{p}}\right]
\end{aligned}
$$

Improvement of the static approach. Let $b$ denote the minimum distance from the axis of the reinforcement column in the cell to the lateral boundary surface $\partial \mathscr{C}_{\mathbf{L}}$. For any radius $c \in[a, b]$, a class of axisymmetrical stress fields is defined

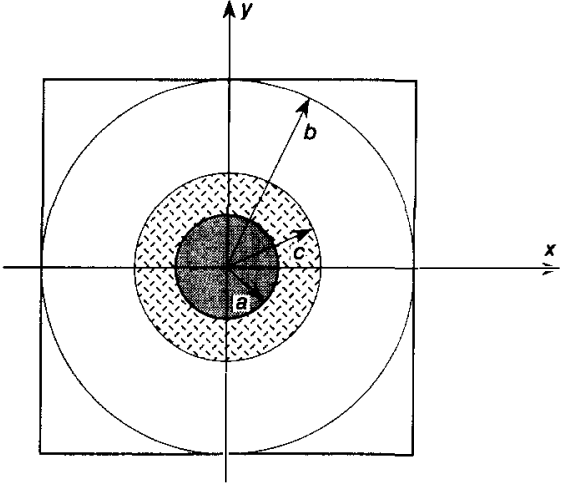

Fig. 3. Three-zone axisymmetrical stress field

in the three intervals $[0, a],[a, c]$ and $r>c$ by (Fig. 3)

$$
\begin{aligned}
& c<r \\
& \quad \sigma_{r r}=\sigma_{\theta \theta}=p ; \sigma_{z z}=p+2 C \\
& a<r<c \\
& \quad \sigma_{r r}=\sigma_{z z} ; \sigma_{\theta \theta}=\sigma_{r r}-2 C \\
& r<a \\
& \sigma_{r r}=\sigma_{\theta \theta} ; \sigma_{z z}=K_{\mathrm{p}} \sigma_{r r}+2 C^{\mathrm{c}} \sqrt{ } K_{\mathrm{p}}
\end{aligned}
$$

(all other $\sigma_{i j}=0$ ). The continuity of the stress vectors acting on the interfaces $r=a$ and $r=c$ implies the continuity of $\sigma_{r r}$ across these surfaces. Using the equilibrium equation (3a) which reduces here to

$$
\frac{\mathrm{d}}{\mathrm{d} r} \sigma_{r r}+\frac{1}{r}\left(\sigma_{r r}-\sigma_{\theta \theta}\right)=0
$$

it is possible to specify the expressions of $\sigma_{r r}$ in the intervals $[a, c]$ and $[0, a]$

$$
\begin{aligned}
& r \in[a, c] \\
& \quad \sigma_{r r}=-2 C \ln (r / c)+p \\
& r \in[0, a] \\
& \sigma_{r r}=2 C \ln (c / a)+p
\end{aligned}
$$

Equations (10) and (11) completely determine a unique stress field $\sigma$ which complies with the strength criteria (equations (1) and (2)) in the domains $r<a$ and $r>a$ respectively. The vertical force equilibrated by such a stress field is

$$
\begin{aligned}
\int_{z=h} \sigma_{z z} \mathrm{~d} S= & S\left(p\left(1-\eta+\eta K_{\mathrm{p}}\right)+2 C^{\mathrm{c}} \eta \sqrt{ } K_{\mathrm{p}}\right. \\
& +2 C\left\{1+\eta\left[\left(K_{\mathrm{p}}-1\right) \ln (x)\right.\right. \\
& \left.\left.\left.-\frac{1}{2}\left(1+x^{2}\right)\right]\right\}\right)
\end{aligned}
$$


where $x$ denotes the ratio $c / a$. Thus, a lowerbound estimate of $Q^{+}(p)$ is obtained for any value of $c \in[a, b]$, i.e. for any $x \in[1, b / a]$

$$
\begin{aligned}
\frac{Q^{+}(p)}{S} \geqslant & p\left(1-\eta+\eta K_{\mathrm{p}}\right)+2 C^{\mathrm{c}} \eta \sqrt{ } K_{\mathrm{p}} \\
& +2 C\left\{1+\eta\left[\left(K_{\mathrm{p}}-1\right) \ln (x)\right.\right. \\
& \left.\left.-\frac{1}{2}\left(1+x^{2}\right)\right]\right\}
\end{aligned}
$$

The maximum value of the right-hand side of equation (13) is achieved for $x=\sqrt{ }\left(K_{\mathrm{p}}-1\right)$. Thus, if $2 \leqslant K_{\mathrm{p}} \leqslant 1+(b / a)^{2}$, the best (i.e. the greatest) lower bound of $Q^{+}(p)$ that can be obtained from this improved static approach is

$$
\begin{aligned}
2 \leqslant K_{\mathrm{p}} \leqslant & 1+\left(\frac{b}{a}\right)^{2} \\
\frac{Q^{+}(p)}{S} \geqslant & p\left(1-\eta+\eta K_{\mathrm{p}}\right)+2 C^{\mathrm{c}} \eta \sqrt{ } K_{\mathrm{p}} \\
& +C[2(1-\eta)+\eta \mathrm{g}(\varphi)]
\end{aligned}
$$

where $\mathrm{g}(\varphi)$ is the following function of the friction angle $\varphi$

$$
\mathrm{g}(\varphi)=\left(K_{\mathrm{p}}-1\right) \ln \left(K_{\mathrm{p}}-1\right)-\left(K_{\mathrm{p}}-2\right)
$$

For $K_{\mathrm{p}} \geqslant 2$, the difference $\Delta=\eta C \mathrm{~g}(\varphi)$ between the lower-bound estimates of $Q^{+}(p)$ given in equations (9) and (14) is a positive number. In other words the second static approach improves the first one as soon as $\varphi \geqslant 19 \cdot 5^{\circ}$, which is always satisfied in the case of a column made up of a purely frictional material, where the friction angle is usually of the order of $35^{\circ}$ (stone columns). The second condition, $K_{\mathrm{p}} \leqslant 1+(b / a)^{2}$, will also be achieved for the usual values of $\varphi, a$ and $b$ encountered in practice. It is assumed below that this condition is always satisfied.

If $K_{\mathrm{p}} \leqslant 2\left(\varphi \leqslant 19 \cdot 5^{\circ}\right)$, which could correspond to the case of lime columns, the best lower-bound estimate of $Q^{+}(p)$ provided by equation (13) is obtained for $x=1$. For this value of $x$, the present static approach reduces to equation (9). It is now established by means of a kinematic approach that equation (14) when $2 \leqslant K_{\mathrm{p}} \leqslant 1$ $+(b / a)^{2}$ and equation (9) when $K_{\mathrm{p}} \leqslant 2$ give the exact limit load that can be sustained by the composite cell.

\section{Upper-bound estimate by means of the kinematic approach}

For any kinematically admissible velocity field $U$ (see equation (4)), the kinematic theorem (Chen, 1975; Salençon, 1983, 1990) provides a necessary condition of stability in the form of the inequality

$$
0 \leqslant Q \leqslant Q^{+}(p) \Rightarrow \mathscr{W}_{\text {ext }}(\boldsymbol{U}) \leqslant \mathscr{W}_{\text {res }}(\boldsymbol{U})
$$

where $\mathscr{W}_{\text {ext }}(\boldsymbol{U})$ and $\mathscr{W}_{\text {res }}(\boldsymbol{U})$ denote respectively the work of the external forces and the maximum resisting work developed within the composite cell in the velocity field $\boldsymbol{U}$ under consideration.

The external forces acting on the cell are the force $\boldsymbol{Q}$ exerted by the upper plate and the lateral pressure $p$. Then

$$
\mathscr{W}_{\text {ext }}(U)=Q V+\int_{\partial \mathscr{C}_{\mathrm{L}}} p \boldsymbol{U} \cdot \boldsymbol{U} \mathrm{d} S
$$

where $\boldsymbol{n}$ is the inward unit normal to $\partial \mathscr{C}_{\mathrm{L}}$. For a continuous velocity field $\boldsymbol{U}$, the maximum resisting work is defined by the integral of a volume density denoted by $\pi(\mathbf{d})$ which is a function of the strain rate tensor $\mathbf{d}$ associated with $\boldsymbol{U}$

$$
\mathscr{W}_{\text {res }}(\boldsymbol{U})=\int_{\mathscr{\mathscr { C }}} \pi(\mathbf{d}) \mathrm{d} \boldsymbol{\Omega}
$$

For a given strength criterion $\mathrm{f}(\boldsymbol{\sigma}), \pi(\mathbf{d})$ is defined as

$$
\pi(\mathbf{d})=\max _{\boldsymbol{\sigma}}\left(-\sigma_{i j} d_{i j}, \mathrm{f}(\boldsymbol{\sigma}) \leqslant 0\right)
$$

and may be interpreted as the maximum dissipated energy per unit volume. Referring to the eigenvalues of the strain rate tensor $\mathbf{d}$ as $d_{i}(i=1$, 2,3 ), the expressions of $\pi(\mathbf{d})$ are (Salençon, 1983, 1990)

(a) Tresca material (equation (2))

$$
\pi(\mathbf{d})=\left\{\begin{array}{l}
C\left(\sum_{i}\left|d_{i}\right|\right) \text { if } \sum_{i} d_{i}=0 \\
+\infty \text { otherwise }
\end{array}\right.
$$

(b) Mohr-Coulomb material (equation (1))

$$
\pi(\mathbf{d})=\left\{\begin{array}{l}
\frac{C^{\mathrm{c}}}{\tan \varphi}\left(\sum_{i} d_{i}\right) \text { if } \sum_{i} d_{i} \geqslant \sin \varphi \sum_{i}\left|d_{i}\right| \\
+\infty \text { otherwise }
\end{array}\right.
$$

Introducing equations (17) and (18) into equation (16), gives the general expression of the upper bound provided by any velocity field $\boldsymbol{U}$

$$
\begin{aligned}
Q^{+}(p) \leqslant & \frac{1}{V}\left[\int_{\mathscr{C}} \pi(\mathbf{d}) \mathrm{d} \Omega\right. \\
& \left.+\int_{\mathscr{Q}_{\mathrm{L}}}-p \boldsymbol{n} \cdot \boldsymbol{U} \mathrm{d} S\right]
\end{aligned}
$$

Consider now a velocity field of the form $U=$ $U(r) e_{r}-(V / h) z e_{z}$, where the radial velocity $U(r)$ is

(a) for $r<a$ (in the column)

$$
U(r)=\frac{1}{2} r K_{\mathrm{p}}\left(\frac{V}{h}\right)
$$


(b) for $r>a$ (native soil)

$$
U(r)=\frac{1}{2}\left[r+\frac{a^{2}}{r}\left(K_{\mathrm{p}}-1\right)\right]\left(\frac{V}{h}\right)
$$

This velocity field is kinematically admissible with $V$ and remains continuous across the interface $r=a$. The density $\pi(\mathbf{d})$ can be computed from equation (20)

(a) if $r<a$

$$
\pi(\mathbf{d})=\left(K_{\mathrm{p}}-1\right) C^{\mathrm{c}} / \tan \varphi(V / h)
$$

(b) if $r>a$

$$
\begin{aligned}
& \text { if } K_{\mathrm{p}} \leqslant 2: \pi(\mathbf{d})=2 C(V / h) \\
& \text { if } K_{\mathrm{p}} \geqslant 2: r<a \sqrt{ }\left(K_{\mathrm{p}}-1\right) \text { : } \\
& \pi(\mathbf{d})=C\left[1+\left(\frac{a}{r}\right)^{2}\left(K_{\mathrm{p}}-1\right)\right](V / h) \\
& a \sqrt{ }\left(K_{\mathrm{p}}-1\right)<r \text { : } \\
& \pi(d)=2 C(V / h)
\end{aligned}
$$

For the calculation of $\mathscr{W}_{\text {res }}(U)$, two cases have once again to be considered, according to the value of $K_{\mathrm{p}}$

(a) $K_{\mathrm{p}} \leqslant 2$

$$
\mathscr{W}_{\text {res }}(U)=S\left[2 \eta C^{\mathrm{c}} \sqrt{ } K_{\mathrm{p}}+2 C(1-\eta)\right] V(24 \mathrm{a})
$$

(b) $2 \leqslant K_{\mathrm{p}} \leqslant 1+\left(\frac{b}{a}\right)^{2}$

$$
\begin{array}{r}
\mathscr{W}_{\text {res }}(\boldsymbol{U})=S\left\{2 \eta C^{\mathbf{c}} \sqrt{ } K_{\mathrm{p}}+\right. \\
C[2(1-\eta)+\eta \mathrm{g}(\varphi)]\} V
\end{array}
$$

where $\mathrm{g}(\varphi)$ is the function introduced in equation (14).

The (resisting) work of the confining pressure in the velocity field defined in equation (22) can be easily derived from

$$
\begin{aligned}
\int_{\partial \mathscr{C}_{\mathrm{L}}}-U \boldsymbol{e}_{r} \cdot n \mathrm{~d} S & =\int_{\mathscr{C}} \operatorname{div}\left(U \boldsymbol{e}_{r}\right) \mathrm{d} \Omega \\
& =\int_{\mathscr{C}} U^{\prime}(r)+\frac{U(r)}{r} \mathrm{~d} \Omega
\end{aligned}
$$

which leads to

$$
\int_{\partial \boldsymbol{r}_{\mathrm{L}}} p \boldsymbol{D} \cdot \boldsymbol{U} \mathrm{d} S=-p\left(1-\eta+\eta K_{\mathrm{p}}\right) V
$$

Introducing these values of $\mathscr{W}_{\text {res }}(\boldsymbol{U})$ and equation (26) into equation (21), gives two different expressions of an upper-bound estimate for $Q^{+}(p)$ according to the value of $K_{\mathrm{p}}$. It can easily be verified that each of them is equal to the corresponding lower-bound estimate given by equation (14) or equation (9). Finally, a combination of a static and a kinematic approach have yielded the exact value of $Q^{+}(p)$, i.e.

$$
\begin{aligned}
K_{\mathrm{p}} \leqslant 2 & \\
\frac{Q^{+}(p)}{S}= & p\left(1-\eta+K_{\mathrm{p}} \eta\right) \\
& +2 C(1-\eta)+2 C^{\mathrm{c}} \eta \sqrt{ } K_{\mathrm{p}} \\
2 \leqslant K_{\mathrm{p}} \leqslant 1 & +\left(\frac{b}{a}\right)^{2} \\
\frac{Q^{+}(p)}{S}= & p\left(1-\eta+\eta K_{\mathrm{p}}\right)+2 C^{\mathrm{c}} \eta \sqrt{ } K_{\mathrm{p}} \\
& +C[2(1-\eta)+\eta \mathrm{g}(\phi)]
\end{aligned}
$$

\section{Interpretation of the result}

In the case of a homogeneous cell composed of a frictional and cohesive material (friction angle $\varphi^{*}$ and cohesion $C^{*}$ ), the limit load $Q_{*}{ }^{+}(p)$ can readily be derived from the strength criterion (equation (1)), where $\varphi$ and $C^{\mathrm{c}}$ must be replaced by $\varphi^{*}$ and $C^{*}$

$$
Q_{*}{ }^{+}(p) / S=p K_{\mathrm{p}}{ }^{*}+2 C^{*} \sqrt{ } K_{\mathrm{p}}{ }^{*}
$$

with $\quad K_{\mathrm{p}}{ }^{*}=\left(1+\sin \varphi^{*}\right) /\left(1-\sin \varphi^{*}\right), \quad$ which appears to be a linear function of the confining pressure $p$. A simple identification of equations (27) and (28) suggests that the strength of the composite cell as a whole is equal to that which would be obtained by considering the same cell composed of an equivalent frictional and cohesive material defined by

(a) if $K_{\mathrm{p}} \leqslant 2$

$$
\left.\begin{array}{rl}
K_{\mathrm{p}}^{\mathrm{eq}} & =\tan ^{2}\left(\frac{\pi}{4}+\frac{\varphi^{\mathrm{eq}}}{2}\right)=1-\eta+\eta K_{\mathrm{p}} \\
C^{\mathrm{eq}} & =\frac{1}{\sqrt{ } K_{\mathrm{p}}^{\mathrm{eq}}}\left[C^{\mathrm{c}} \eta \sqrt{ } K_{\mathrm{p}}+C(1-\eta)\right]
\end{array}\right\}
$$

(b) if $2 \leqslant K_{\mathrm{p}} \leqslant 1+\left(\frac{b}{a}\right)^{2}$

$$
\left.\begin{array}{rl}
K_{\mathrm{p}}^{\mathrm{eq}}= & \tan ^{2}\left(\frac{\pi}{4}+\frac{\varphi^{\mathrm{eq}}}{2}\right) \\
= & 1-\eta+\eta K_{\mathrm{p}} \\
C^{\mathrm{eq}}= & \frac{1}{\sqrt{K_{\mathrm{p}}^{\mathrm{eq}}}}\left\{C^{\mathrm{c}} \eta \sqrt{ } K_{\mathrm{p}}\right. \\
& \left.+C\left[(1-\eta)+\frac{1}{2} \eta \mathrm{g}(\varphi)\right]\right\}
\end{array}\right\}
$$

In both cases, the equivalent cohesion $C^{\text {eq }}$ thus defined appears to be a function of the proportion of reinforcement $\eta$, and of the strength characteristics $C, C^{\mathrm{c}}$ and $\varphi$, whereas the equivalent 


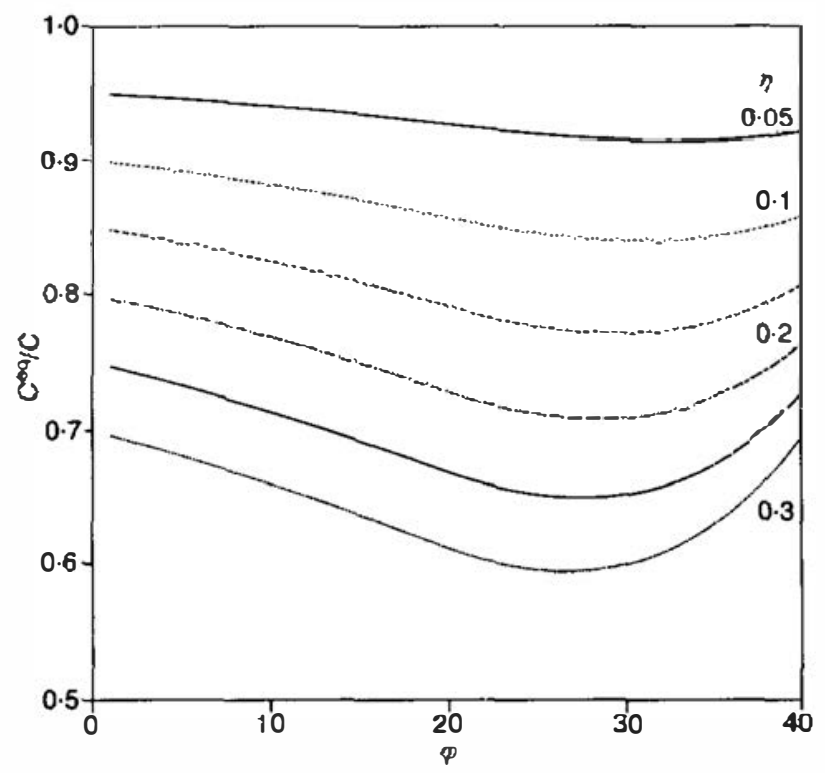

Fig. 4. Equivalent cotresion $C^{\text {eq }}$ for $C^{c}=0$ plotted against friction angle $\varphi$

friction angle $\varphi^{\text {eq }}$ depends solely on $\eta$ and $\varphi$

$$
\begin{aligned}
C^{\mathrm{eq}} / C & =\mathscr{B}\left(\varphi, \eta, C^{\mathrm{c}} / C\right) \\
\varphi^{\mathrm{eq}} & =\mathscr{F}(\eta, \varphi)
\end{aligned}
$$

Equations (29) and (30) show that the equivalent cohesion is a linearly increasing function of $C^{\mathrm{c}} / C$

$$
C^{\mathrm{eq}} / C=\alpha(\eta, \varphi)\left(C^{\mathrm{e}} / C\right)+\beta(\eta, \varphi)
$$

Fig. 4 presents the variation of the ordinate $\beta(\eta$, $\varphi)$ at the origin $\left(C^{\varsigma} / C=0\right)$ for $\eta$ varying between 0.05 and $0.3 . \beta(\eta, \varphi)$ can be interpreted as the equivalent cohesion in the case of a purely frictional column material. This equivalent cohesion

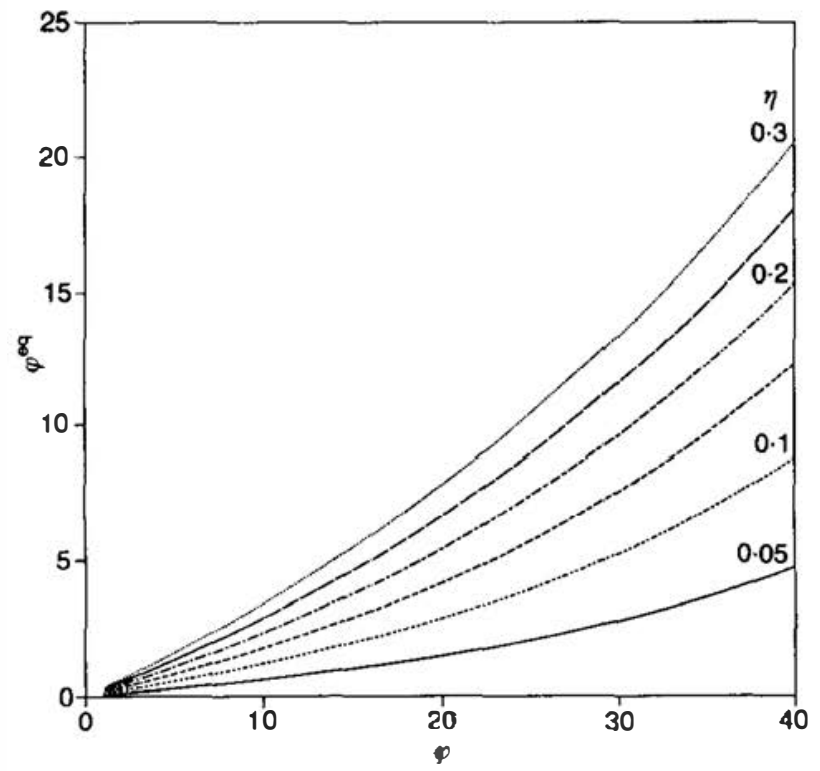

Fig. 5. Equivalent friction angle $\varphi^{* 4}$ plotted against friction angle $\varphi$ turns out to be smaller than that of the original soil and decreases significantly for increasing values of the surface ratio $\eta$. Indeed, in this case, the reinforcement effect is entirely due to the frictional properties of the column material and can be quantitatively measured by the equivalent friction angle $\varphi^{\text {eq }}$.

Likewise, Fig. 5 presents the variation of the equivalent friction angle $\varphi^{\text {eq }}$ as a function of $\varphi$ for several values of the surface ratio ranging from 0.05 to $0.3 . \varphi^{\bullet 4}$ is, as expected, an increasing function of both $\eta$ and $\varphi$ which reaches $19^{\circ}$ for $\eta=0.3$ and $\varphi=38^{\circ}$.

\section{BEARING CAPACITY OF A FOUNDATION}

The problem of the bearing capacity of a smooth and rigid footing on a soil layer $\Omega$ of limited depth $d$ which occupies the region $-d \leqslant z \leqslant 0$ (Fig. 6) is now considered. This soil has been reinforced by a group of vertical columns in the region located beneath the foundation. The area of contact between the footing and the soil layer is located in the plane $z=0$. The strength of the column material and that of the native soil are again described by equations (1) and (2) respectively. In this section, a truly three-dimensional static approach is applied to determine a lower-bound estimate for the bearing capacity $Q^{+}$. It is then shown how the same result can be obtained from very simple reasoning making use of the notion of equivalent material already introduced.

Three-dimensional static approach to $Q^{+}$

In order to achieve a result that could be applied to a wide range of practical situations, the approach is not restricted to a particular shape of the footing or to a particular distribution of the columns below the foundation. However, for the sake of simplicity, all columns are supposed to

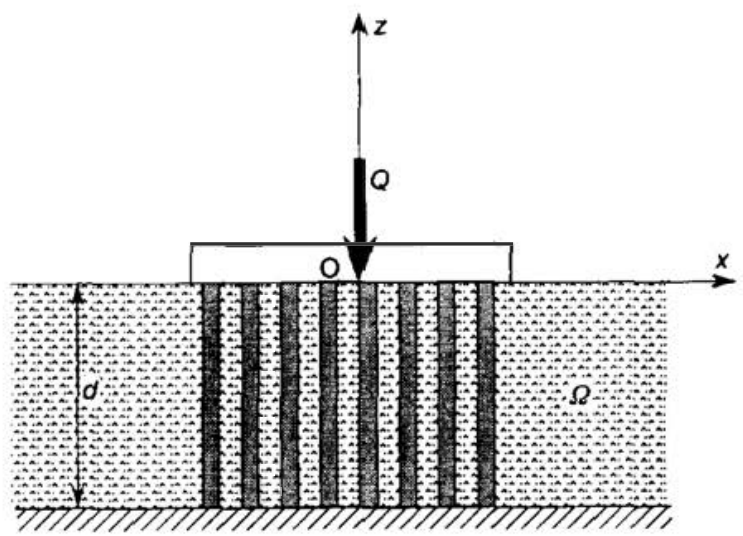

Fig. 6. Rigid footing on a soil reinforced by a group of columns 
have the same radius $a$. The ratio between the total cross-sectional area of the reinforcement and the footing area is therefore $\eta=N \pi a^{2} / \mathscr{A}$, where $N$ is the number of columns. Gravitational forces are not considered in this analysis.

A given vertical load $Q$ applied to the soil by means of the footing is safe (i.e. $Q \leqslant Q^{+}$) in the sense of yield design if it can be equilibrated by a stress field $\sigma$ that satisfies the conditions

$$
\begin{aligned}
& \frac{\partial}{\partial x_{j}}\left(\sigma_{i j}\right)=0 \\
& \left.\begin{array}{l}
\sigma_{x z}=\sigma_{y z}=0 \\
\int_{(\mathscr{A})} \sigma_{z z} \mathrm{~d} S=Q
\end{array}\right\}(\mathscr{A}) \\
& \left.\sigma_{x z}=\sigma_{y z}=\sigma_{z z}=0 \quad(z=0)-(\mathscr{A})\right]
\end{aligned}
$$

in the columns: $f_{1}(\sigma) \leqslant 0$

in the native soil: $f_{2}(\sigma) \leqslant 0$

In the construction of such a stress field, the result already obtained is used.

Static approach using a piece-wise constant stress field. Consider first the stress field defined as follows

(a) outside the domain located below the area

$$
\sigma_{x x}=\sigma_{y y}=2 C ; \sigma_{z z}=0 ; \text { other } \sigma_{i j}=0
$$

(b) below the area $(\mathscr{A})$

in the native soil

$$
\sigma_{x x}=\sigma_{y y}=2 C ; \sigma_{z z}=4 C ; \text { other } \sigma_{i j}=0
$$

in the columns

$$
\begin{array}{r}
\sigma_{x x}=\sigma_{y y}=2 C ; \sigma_{z z}=K_{\mathrm{p}} 2 C+2 C^{\mathrm{c}} \sqrt{ } K_{\mathrm{p}} ; \\
\text { other } \sigma_{i j}=0
\end{array}
$$

The continuity of the stress vector and the compatibility of $\sigma$ with the strength criteria are obviously satisfied. It can be easily verified that the stress field $\boldsymbol{\sigma}$ defined above is statically admissible with the force $Q_{\ell}$ given by

$$
Q_{\ell \ell} / \mathscr{A}=4 C+2 \eta\left[C\left(K_{\mathrm{p}}-2\right)+C^{\mathrm{c}} \sqrt{ } K_{\mathrm{p}}\right]
$$

This equation provides a first lower-bound estimate of $Q^{+} / \mathscr{A}$ which offers the advantage of being valid without restricting the geometrical characteristics or the strength parameters.

Improvement of the static approach in the case $K_{\mathrm{p}} \geqslant 2$. Consider the following cases.

(a) Outside the domain located below the area $(\mathscr{A})$, the stress field is the same as in equation (34). (b) Below the area $(\mathscr{A})$, let $D$ be the minimal distance between the axes of two columns. Around each column $i$ a circular cylinder denoted $\mathscr{C}_{i}$ of radius $c=x a$ is defined, where $x$ is a fixed parameter chosen in the interval $[1, D / 2 a]$ so that two different cylinders $\mathscr{C}_{i}$ and $\mathscr{C}_{j}$ cannot intersect each other (Fig. 7).

In the region outside such cylinders $\mathscr{C}_{i}$, the stress field is as given in equation (35a). Inside each of them the construction of the stress field is the same as already given where $2 C$ is substituted for $p$ in equations (10a) and (11) to ensure the continuity of the stress vector across the boundary of $\mathscr{B}_{i}$. Thus

(a) $a \leqslant r \leqslant c$ (in the native soil)

$$
\begin{aligned}
& \sigma_{r r}=\sigma_{z z}=2 C\left[\log \left(\frac{c}{r}\right)+1\right] ; \\
& \sigma_{\theta \theta}=\sigma_{r r}-2 C
\end{aligned}
$$

(b) $r \leqslant a$ (in the column)

$$
\begin{aligned}
& \sigma_{r r}=\sigma_{\theta \theta}=2 C[\log (x)+1] ; \\
& \sigma_{z z}=K_{\mathrm{p}} \sigma_{r r}+2 C^{\mathrm{c}} \sqrt{ } K_{\mathrm{p}}
\end{aligned}
$$

This stress field $\sigma$ is in equilibrium with the force $Q(x)$ given by

$$
\begin{aligned}
Q(x)= & \mathscr{A}\left(4 C+2 C^{\mathrm{c}} \sqrt{ } K_{\mathrm{p}} \eta+2 C \eta\right. \\
& \times\left\{\left(K_{\mathrm{p}}-1\right)[\log (x)+1]\right. \\
& \left.\left.-\left(1+x^{2}\right) / 2\right\}\right)
\end{aligned}
$$

The optimal choice of $x$ in the interval $[1, D / 2 a]$ is $\sqrt{ }\left(K_{\mathrm{p}}-1\right)$ and yields

$$
\begin{aligned}
Q_{\ell} / \mathscr{A}= & 4 C+2 \eta\left[C\left(K_{\mathrm{p}}-2\right)+C^{\mathrm{c}} \sqrt{ } K_{\mathrm{p}}\right] \\
& +C \eta \mathrm{g}(\varphi)
\end{aligned}
$$

which constitutes a better lower-bound estimate of $Q^{+}$than equation (36) as it is obtained by adding the quantity $C \eta \mathrm{g}(\varphi)$ (positive for $K_{\mathrm{p}} \geqslant 2$ ) to equation (36). The validity of equation (39) is subject to the condition $K_{\mathrm{p}} \leqslant 1+(D / 2 a)^{2}$.

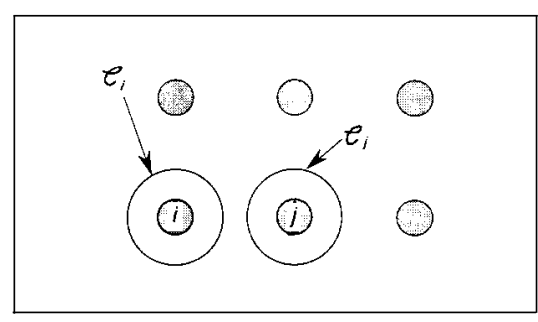

Fig. 7. Zoning of the mass of soil below the foundation 
Interpretation based on the concept of equivalent material

The previous result may be interpreted based on the concept of equivalent material and related notions of equivalent cohesion $C^{\text {eq }}$ and friction angle $\varphi^{\mathrm{eq}}$, as introduced with reference to the composite cell. Indeed, adopting a heuristic point of view, one could be tempted to substitute the equivalent material thus defined for the heterogeneous reinforced soil, so that the solution of the initial bearing capacity problem (Fig. 8(a)) would reduce to that of the equivalent problem shown in Fig. 8(b).

Proceeding further with this kind of reasoning, a simple static approach can be implemented on the latter problem by considering the following stress field

(a) within the zone composed of the equivalent material

$$
\left.\begin{array}{l}
\sigma_{x x}=\sigma_{y y}=2 C ; \\
\sigma_{z z}=2 C K_{\mathrm{p}}^{\mathrm{eq}}+2 C^{\mathrm{eq}} \sqrt{K_{\mathrm{p}}^{\mathrm{eq}}}
\end{array}\right\}
$$

(b) outside this zone

$$
\sigma_{x x}=\sigma_{y y}=2 C ; \sigma_{z z}=0
$$

Such a stress field obviously complies with the strength criteria of the original soil and of the equivalent material in each of the two zones. It equilibrates the force

$$
Q_{\ell \theta^{e q}}=2 \mathscr{A}\left(C K_{\mathrm{p}}{ }^{\mathrm{eq}}+C^{\mathrm{eq}} \sqrt{ } K_{\mathrm{p}}{ }^{\mathrm{eq}}\right)
$$

which could be interpreted as a lower-bound estimate for the equivalent bearing capacity problem. Now, referring to equations (29) and (30), it appears immediately that $Q_{68}{ }^{24}$ is identical with the lower-bound estimate $Q_{\ell 6}$ given for the initial problem by equations (36) and (39) for $K_{\mathrm{p}} \leqslant 2$ and $K_{\mathrm{p}} \geqslant 2$ respectively.

However, the concept of equivalent material should be handled very cautiously as it bears no significance apart from the particular situation where the reinforced soil is submitted to a triaxial loading (axisymmetrical about the direction of reinforcement). It does not apply, for example, to the description of the overall strength properties of the reinforced soil when subjected to off-axis forces. To attempt to implement a static approach on the equivalent problem, using stress fields with inclined principal directions, would lead to completely misleading conclusions.

The idea of homogenization, which is only partially conveyed in the notion of equivalent material, can be rigorously formulated (de Buhan \& Salençon, 1990). It relies on the assumption that the reinforcing inclusions are regularly distributed throughout the soil mass, and that the spacing between two such successive inclusions can be considered small enough when compared with a characteristic length of the problem, such as the width of the footing. Such a theoretical approach has already been successfully applied in the geotechnical field to the design of reinforced earth structures (de Buhan, Mangiavacchi, Nova, Pellegrini \& Salençon, 1989). Contrary to what might be suggested by the preceding notions of equivalent cohesion and friction angle, it provides clear evidence of the anisotropic strength properties of the reinforced soil as a homogeneous material.

\section{Quantitative assessment of the bearing capacity improvement}

Although the exact value of the bearing capacity remains unknown, and only lower-bound estimates $Q_{\ell \ell}(\eta)$ given by equations (36) and (39) are available, it seems reasonable to assess the bearing capacity improvement due to the reinforcement by means of the ratio $R=$ $Q_{\ell \varnothing}(\eta) / Q_{\ell \varnothing}(0)$, where $Q_{\ell \varnothing}(0)$ represents the value of the lower bound obtained for the unreinforced structure $\left(Q_{\ell \ell}(0)=4 \mathscr{A C}\right)$

(a) for $K_{\mathrm{p}} \leqslant 2$

$$
\left.\begin{array}{l}
R=1+\frac{\eta}{2}\left[\left(K_{\mathrm{p}}-2\right)+\frac{C^{\mathrm{c}}}{C} \sqrt{ } K_{\mathrm{p}}\right] \\
\text { (b) for } K_{\mathrm{p}} \geqslant 2 \\
R=1+\frac{\eta}{2}\left[\left(K_{\mathrm{p}}-2\right)+\frac{C^{\mathrm{c}}}{C} \sqrt{ } K_{\mathrm{p}}\right]+\frac{\eta}{4} \mathrm{~g}(\varphi)
\end{array}\right\}
$$

where $\mathrm{g}(\varphi)$ is as given in equation (15). As is apparent from this equation, the reinforcement

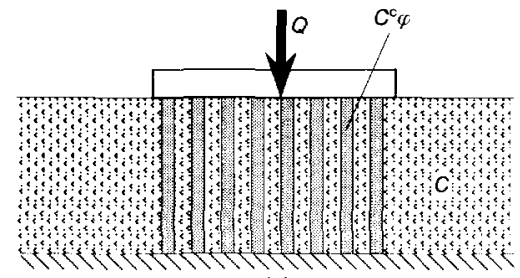

(a)

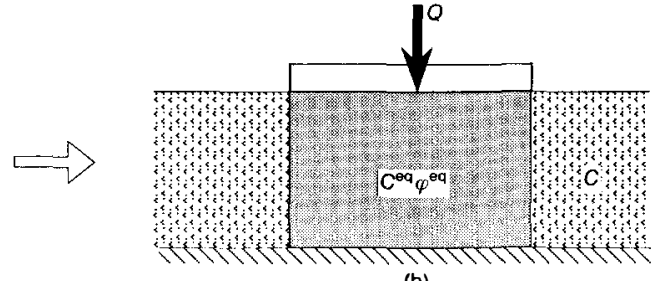

(b)

Fig. 8. Bearing capacity problem: (a) initial; (b) equivalent 
effect can be attributed to both the cohesive (through $C^{\mathrm{c}} / C$ ) and the frictional properties (through $\varphi$ or $K_{\mathrm{p}}$ ) of the column material. The increase of (the lower-bound estimate of the bearing capacity is directly proportional to the volume fraction of the columns.

All these results are summarized in Fig. 9 where the contour lines of $R$ (called the bearing capacity enhancement factor) as a function of the non-dimensional strength parameters of the reinforcing material $\left(C^{\mathrm{c}} / C, \varphi\right)$ are represented for three typical values of its proportion $(\eta=0 \cdot 1,0 \cdot 2$ and $0 \cdot 3$ ). Assuming, for example, that the columns are placed into the foundation soil following a periodic square-shaped mesh, these values correspond approximately to $2 a / D=0.36,0.50$ and $0 \cdot 62$, where $2 a$ is the diameter of the columns and $D$ their horizontal spacing.

Two situations commonly encountered in practice are now examined.

Reinforcement by stone columns. The reinforcing material is a compacted sand or gravel with a high friction angle $\left(\varphi=35^{\circ}-40^{\circ}\right)$ and practically no cohesion $\left(C^{\mathrm{c}} / C=0\right)$. The enhancement of the bearing capacity of a foundation lying on such a reinforced soil remains limited. Thus, for $\eta=0 \cdot 2$, the reinforcing factor can barely reach the value 1.5. This theoretical result confirms the idea that increasing the bearing capacity is not the prime objective of this kind of reinforcement.

Reinforcement by lime columns. The constituent material is obtained by mixing a small proportion of lime with the in situ clay, thus increasing the strength of the latter by a factor of up to 20 . Although significantly lower than in the case of the stone column material, a friction angle can also be measured. As can be seen from Fig. 9(b) (for $\eta=0 \cdot 2$ ), the bearing capacity can easily be increased threefold even if a zero friction angle is assumed.

\section{CONCLUSIONS}

The improvement of the bearing capacity of a foundation soil expected from its reinforcement by columns has been investigated in two stages. First, a triaxial loading test on a representative volume comprising a single column of reinforcement was simulated. The strength properties of such a composite cell expressed in terms of compressive force and confining pressure have been determined exactly through the combined implementation of the yield design static and kinematic approaches. Such a study paves the way for a possible experimental validation of the theoretical predictions.

Making use of the optimal stress field exhibited in the static solution of the composite cell model, a general lower-bound estimate for the bearing

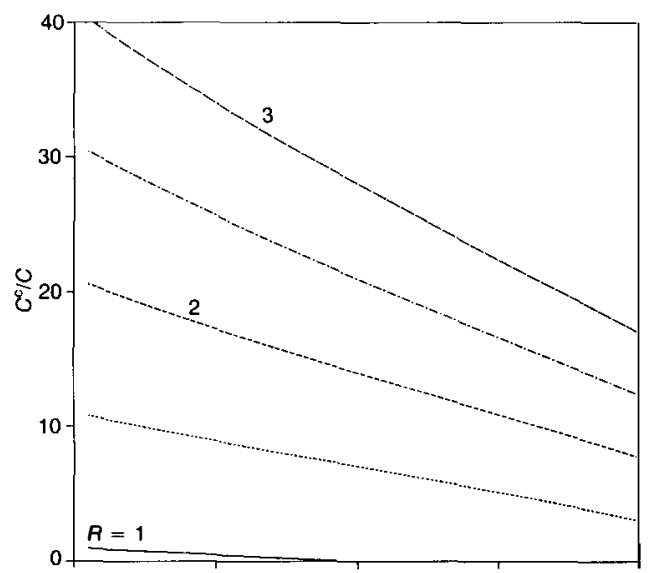

(a)

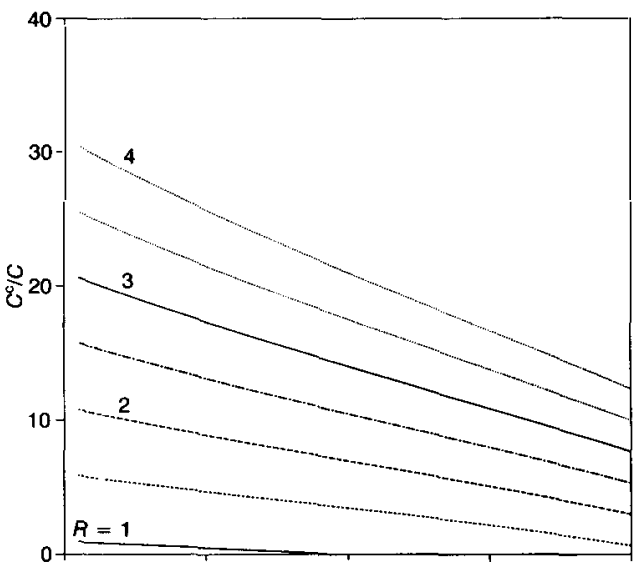

(b)

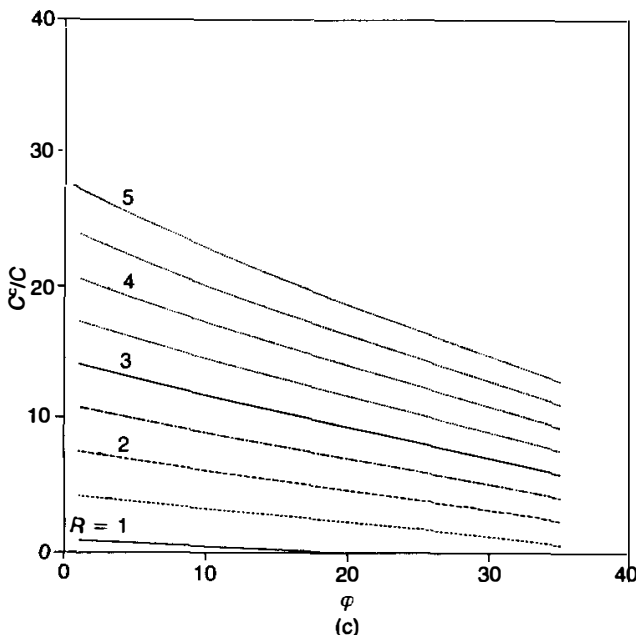

Fig. 9. Contour lines of the bearing capacity enhancement factor $R$ : (a) $\eta=0.1$, (b) $\eta=0.2$; (c) $\eta=0.3$ 
capacity of a foundation-raft lying on a soil reinforced by a group of columns was then determined in the form of readily usable analytical expressions. The main interest of this estimate lies in the fact that it provides a reliable assessment for the three-dimensional bearing capacity problem, regardless of the shape of the foundation and the geometrical arrangement of the columns. It is a convenient engineering design tool, allowing the efficiency of different technical solutions to be compared in terms of bearing capacity improvement. Moreover, it can be shown that the range of applicability of the lower-bound solution developed in this Paper (equations (36) and (39)) can be extended to take gravitational forces into account, and to the case where the strength properties of the column material are expressed in terms of effective stresses. However, it remains to be seen whether this lower-bound solution is sufficiently close to the exact value of the bearing capacity. This could be determined by implementing upperbound kinematic solutions for the problem, provided that the shape of the foundation and the exact distribution of the columns were specified, in which case a homogenization method should probably be used.

\section{NOTATION}

$a$ radius of the column

$\mathscr{A}$ surface of the foundation

$C$ cohesion of the native soil

$C^{\mathrm{c}}$ cohesion of the reinforcing material

$C^{\text {eq }}$ cohesion of the equivalent material

$D$ minimal distance between the axes of two columns

$K$ domain of safe loads $(Q, p)$ applied to the composite cell

$K_{p}$ coefficient of passive stress of the reinforcing material

$K_{p}^{e q}$ coefficient of passive stress of the equivalent material

$Q_{\ell \text { l }}$ lower-bound estimate of the foundation bearing capacity

$Q^{+}(p)$ maximum force sustained by the cell for a confining pressure $p$

$R$ bearing capacity enhancement factor $Q_{\text {ed }}(\eta) / Q_{\text {ed }}(0)$

$\eta$ proportion of the reinforcement $\varphi$ friction angle of the reinforcing material

$\varphi^{\text {eq }}$ friction angle of the equivalent material

\section{REFERENCES}

Aboshi, H., Ichimoto, E., Enoki, M. \& Harada, K. (1979). The composer: a method to improve characteristics of soft clays by inclusion of large diameter sand columns. Proc. Int. Colloq. Soil Reinforcement, Paris, vol. 1, pp. 211-216.

Balaam, N. P. \& Booker, S. R. (1985). Effect of stone column yield on settlement of rigid foundations in stabilized clay. Int. J. Numer. Analyt. Methods Geomech. 9, No. 4.

Brauns, J. (1978). Die Anfangstraglast von Schottersäulen im bindingen Untergrund. Bautechnik 8, 263271.

Broms, B. B. \& Boman, P. (1979). Lime columns-a new foundation method. J. Geotech. Engng Div. Am. Soc. Civ. Engrs 105, GT4, 539-556.

de Buhan, P., Mangiavacchi, R., Nova, R., Pellegrini, G. \& Salençon, J. (1989). Yield design of reinforced earth walls by a homogenization method. Géotechnique 39, No. 2, 189-201.

de Buhan, P. \& Salençon, J. (1990). Yield strength of reinforced soils as anisotropic media. In Yielding, damage and failure of anisotropic soils (ed. J. P. Boehler), EGF5, pp. 791-803. London: Mechanical Engineering Publications.

Chen, W. F. (1975). Limit analysis and soil plasticity. Elsevier.

Hughes, J. M. \& Withers, N. J. (1974). Reinforcing of soft cohesive soils with stone columns. Ground Engng 42.

Madhav, M. R. \& Vitkar, P. P. (1978). Strip footing on weak clay stabilized with granular trench or pile. Can. Geotech. J. 15, 605-609.

Pruchnicki, E. \& Shahrour, I. (1991). Application de la théorie de l'homogénéisation aux colonnes ballastées. Ann. Inst. Tech. Bâtim., No. 496, Série sols et fondations $213,117-127$.

Salençon, J. (1983). Calcul à la rupture et analyse limite. Paris: Presses de L'Ecole Nationale des Ponts et Chaussées.

Salençon, J. (1990). An introduction to the yield design theory and its application in soil mechanics. Eur. $J$. Mech. A9, No. 5, 477-500.

Schweiger, H. F. \& Pande, G. N. (1986). Numerical analysis of stone column supported foundations. Comput. Geotech. 2, 347-372.

Soyez, B. (1985). Méthodes de dimensionnement des colonnes ballastées. Bull. Liais. Labs Ponts Chauss., No. 135, 35-51. 